\title{
The ethics of rebuilding our country's surgical platform after a pandemic
}

\author{
Erica F. Robinson, Brian C. Brost, Janelle K. Moulder \\ Department of Obstetrics and Gynecology, Wake Forest School of Medicine, Winston-Salem, North Carolina, United States
}

Received: June 25, 2020

DOI: $10.5430 /$ jha.v9n3p30
Accepted: July 10, 2020

URL: https://doi.org/10.5430/jha.v9n3p30

\begin{abstract}
The COVID-19 pandemic has shaken the foundation of our healthcare system. One of the most dramatic consequences is the postponement of elective surgical procedures, which has led to significant financial stress. As institutions plan to reintegrate their surgical case backlog back into the operating room, there are many factors to consider. Now, more than ever, efficiency and cost-savings must be considered, but these factors must not overshadow the commitment to caring for our patients and communities.
\end{abstract}

Key Words: Ethics, Surgery, Pandemic

\section{INTRODUCTION}

Pandemics and environmental disasters are some of the most disruptive and destructive forces on a healthcare system. On March 11, 2020 a global pandemic was declared by the World Health Organization (WHO) in response to the escalation of novel coronavirus (COVID-19) infections and subsequent deaths. ${ }^{[1]}$ Within the week, the United States Surgeon General advised hospitals to cancel elective surgeries to minimize the spread of the coronavirus, decrease use of personal protective equipment (PPE), and preserve the hospital workforce needed to fight the impending pandemic. ${ }^{[2]}$ The American College of Surgeons (ACS) also released a statement regarding the management of elective surgical procedures, with a call to "thoughtfully review" all scheduled elective procedures and "immediately minimize use of essential items."[3] With an appropriate and abrupt cessation of surgical procedures, many hospitals have seen patient volumes plummet in anticipation of a surge in COVID-19 infections. ${ }^{[4,5]}$ As surgical procedures are the financial lifeblood of most hospital systems, reintegration of postponed cases and scheduling of new elective cases will require both strategic and ethical considerations to provide efficient and high-quality patient care while returning to financial solvency.

\section{ECONOMIC IMPLICATIONS OF A PAN- DEMIC: THE COVID-19 EXPERIENCE}

Prior to the COVID-19 pandemic, the American healthcare system already showed signs of stress as it worked to meet the needs of insured, underinsured, and uninsured patients. Rapidly rising unemployment has dramatically impacted our patients. Unemployment affects access to benefits, such as private insurance, which contributes to the complexity of a cumbersome system. Healthcare costs remain a source of stress for many Americans, with two-thirds of Americans reporting concerns about unexpected medical bills. ${ }^{[6]}$ As these data predate the pandemic, the percentage is likely to be higher in this time of growing medical and financial uncertainty. Beyond these personal stressors, hospital systems are also dramatically affected by this economic decline.

${ }^{*}$ Correspondence: Erica F. Robinson; Email: E.Robinson@wakehealth.edu; Address: Department of Obstetrics and Gynecology, Wake Forest School of Medicine, Winston-Salem, North Carolina, United States. 
3. INSTITUTIONAL FINANCIAL STABILITY: BALANCING MEDICINE, BUSINESS, AND ETHICS

The majority of hospitals maintain financial stability by relying on the completion of "elective procedures." Elective procedures are medically recommended, but not necessarily immediately life-saving, and typically scheduled without urgency. For hospitals following the current recommendations, most elective procedures have been postponed since mid-March, when concerns regarding the novel coronavirus turned into a pandemic. As the shortage of PPE became a challenge across the nation, hospitals faced increased acquisition costs of necessary items for their staff. Additionally, some hospitals paid more to employees in overtime or hazard pay. Hospitals hard hit by COVID-19 infected patients also paid for temporary workers to supplement their strained workforce.

While some hospitals and healthcare systems are large enough to weather a significant downturn in institutional revenue, small, rural, and safety-net hospitals are less likely survive this pandemic without substantial assistance. Safetynet hospitals, (those primarily serving the uninsured, Medicare, or Medicaid patients) function on a narrow margin. ${ }^{[7]}$ Over the last decade, rural hospitals have also struggled financially in light of lower reimbursements, decreasing patient populations, and higher operational costs. ${ }^{[8]}$ More than 100 rural hospitals have closed in the past decade, and many more are projected to close secondary to the economic impact of this pandemic. ${ }^{[9]}$ Their closure may result in greater harm to their communities by reducing access to healthcare, jeopardizing non-maleficence.

When the pandemic plateaus, some hospitals will have the luxury of returning to their prior business model for financial sustainability, while others will not survive-the pandemic effectively shuttering these institutions indefinitely. For those that survive, the reopening of their surgical services will lay the foundation to rebuild their financial sustainability. For the inevitable closures, rural and uninsured hospital communities will be further isolated from receiving necessary healthcare. To avoid a setting of entropic disaster, the speed and efficiency of each hospital's return to financial and personnel stability will rely on balancing multiple factors.

\section{Prioritizing Cases}

\subsection{Surgeon specific solutions: A focus on justice and beneficence}

As operating room (OR) time is unlikely to return at full volume, surgeons will be approached to reprioritize their delayed surgeries and integrate the surgeries that have con-

Published by Sciedu Press tinued to accumulate. This need to integrate a large volume of surgeries into limited OR time will strain the system. Independent of other healthcare stakeholders (i.e. hospitals, patients, ancillary support staff, payer mix and others), surgeons will likely triage cases by acuity and then by order originally scheduled. This follows the ethical principles of justice, fidelity, and beneficence. It aligns with an internal barometer of "fairness." This approach includes a predictable method to triage the sickest and most acute patients into the first wave of cases. Then, the remainder of cases are placed on a "sliding scale" of need and harm-prevention, followed by the length of time inconvenienced by the delay in their surgery.

In an isolated setting, surgeon-directed determination of case prioritization and order makes sense. However, following the pandemic, a number of hospital systems will be in dire financial circumstances. With this in mind, does beneficence take a different meaning? Is beneficence ("doing the most good for the most people") broadened to encompass fiscal responsibility to ensure the continued presence of the institution within a community? Should cases now be prioritized based on payer, in order to support this comprehensive definition of beneficence? This likely places the surgeon, patient and institution in opposition depending on priority alignment.

\subsection{Societal Implications: a focus on non-maleficence}

During this time of shifting healthcare coverage for many Americans, the potential costs of postponed or pending elective procedures comes into sharper contrast. One of the many unfortunate consequences of postponing surgeries is the potential progression of disease or illness compounded by the financial impact through job and/or insurance loss due to the recent economic downturn. "Charity care" programs may be suspended or decreased in the current economy while institutions work towards improved financial stability. Therefore, while the medical justification for their procedure or healthcare may be sound, the burden of financial ruin is real, and a large number of these postponed cases will be cancelled, but is that just? Patients with unscheduled or delayed surgical care are more likely to access emergency room services at greater cost to the institutions without treating the underlying conditions. For these individuals, an argument could be made for expediting their procedures to avoid additional financial hardship or potential bankruptcy, and avoid utilization of emergency services. As a healthcare system, we must be forthcoming with patients regarding cost and risk for their planned procedure; patients should be allowed to make informed and autonomous decisions regarding the impact beyond their health. 


\subsection{Institutional finances: Balancing the business and ethics of medicine}

The reintegration of elective surgical cases should occur in a phased approach. As hospitals evaluate their backlog of cases, there will be disproportionate numbers of cases among service lines and varying levels of medical acuity. The variation in cases and acuity are almost impossible to compare directly across service lines. As such, a departmental surgeon-champion should determine the internal metric of medical acuity and prioritization. Distribution of OR time among services is then considered with regard to volume of cases, time to complete postponed cases, prior block-time distribution, payer mix, margin of reimbursement, and other factors.

Each service line will advocate for increased OR time. It is the nature of surgeons and surgical work. However, for the health of the institution, prioritization of higher margin elective (but still medically necessary) surgeries that can be completed quickly may take precedence in order to help reestablish financial stability. To balance the discrepancy between service line case volume (keeping the high margin concept in mind), an equitable and proportional distribution of OR time may need to be considered. Institutions should consider their unique factors influencing the reintegration of cases. But the goal to optimize service line functionality for the betterment of all should include: minimizing cancellation rates, maximizing efficiency and working with transparency and integrity.

\subsection{A strategic, phased approach to reopening non time- essential cases: upholding justice at the societal, pa- tient and surgeon level}

When COVID-19 has reached endemic levels, a strategic return of non-time essential cases must occur. This reintegration offers opportunity to optimize efficiencies and balance the allocation of resources (e.g. PPE, redistribution of staff to OR coverage). With improved efficiency comes increased ability to manage the surge in surgical volume and optimize non-maleficence and beneficence with the timely completion of these procedures. Traditionally, two primary strategies are employed to increase surgical volume and patient access to care: develop additional surgical suites and/or improve surgical efficiency. ${ }^{[10]}$ With a large national surgical case backlog, institutions must focus inwardly on the improvement of their surgical efficiency in both room scheduling and team scheduling. As surgical volume surges, pre- and post-operative bottlenecks can be avoided by proportionally optimizing and augmenting these perioperative pathways. ${ }^{[11]}$ While post-anesthesia care unit(s) and postoperative beds are distributed differently across hospitals, any surge in surgical patients will further strain a potentially already at-capacity facility. Deliverate and pre-emptive planning of postoperative destinations is essential. Increased efficiency in perioperative services will increase capacity, and therefore revenue, for hospitals.

Batching similar cases, completed by an efficient, highvolume surgeon who has low complication rates, and scheduled with a service-specific OR team is an efficient way to decrease case duration, ${ }^{[12-14]}$ thus allowing for optimized time utilization. With efficient ORs and increased surgical case throughput, hospital revenue increases. As mentioned before, this allows for faster return to "charity care" services for the hospital, better community care opportunities, and a continued presence in the community to provide care for the patients in need. Without this revenue, hospitals are facing furloughs, staffing reductions, and some are closing their doors permanently.

The integration of learners, while beyond the scope of this paper, deserves mention. Learners in the surgical environment affect surgical efficiency, time, and resources. Procedures that are typically performed by a single surgeon should not have learners or learner participation should be limited based on resource availability. Procedures that require more than one surgeon for safe completion would require limitations to the number of learners or assistants scrubbed per case, as each would require the full complement of PPE. From the perspective of surgical efficiency, the goal is to reintegrate learners as safely and resourcefully as possible while respecting limitations. These are just a few factors to consider to optimize surgical case times and efficiency. With appropriate efficiency measures of stacking cases, the learner can participate at increasing amounts as the day progresses. With like cases batched together, the last case of the day (after seeing several), is optimal for increased trainee involvement. For many learners, who may be dramatically impacted, options for future sub-internships would be encouraged for further direct surgical involvement as ORs, surgeons, staff, and resources adjust to our new endemic COVID levels.

Cost optimization is achieved by an institutional standardized approach to surgical cases. While the standardization of surgical trays has been shown to decrease the equipment costs, purchase of new equipment is difficult in our current setting of institutional financial constraints. A variety of disposable and non-disposable equipment can be used interchangeably without compromising the surgical outcome. Surgeons can increase the procedural financial margin by utilizing equipment with similar functions but lower costs. As an example, common energy sources (or even suture selection) may be equally appropriate for a surgery, but costs can vary significantly. While a single suture does not impact the bottom line, 
widespread changes across service lines, institutions and/or health systems does result in improved case margins.

A final, and often overlooked, cost-effective modality is the integration of office-based procedures: both diagnostic and therapeutic. While this may represent a specialty-specific strategy, these office-based procedures are often favorably reimbursed, and they decrease utilization of OR time, hospital fees, and need for anesthesia. Consequently, office procedures also alleviate stress on inpatient and outpatient operating rooms, which allows for appropriate utilization by specialties or surgeons without this option. In gynecology, the chief example is office hysteroscopy-visualization of the endometrial cavity with a distending media for the evaluation of structural abnormalities. As a clean-contaminated procedure with minimal patient discomfort, office hysteroscopy is well suited for patients needing a diagnostic procedure, with an estimated cost savings of $\$ 1,500$ per patient. ${ }^{[15]}$ The corollary in urology and urological gynecology is cystoscopy to evaluate the bladder, with in-office cystoscopy occurring at a fraction of the cost of a hospital-based procedure.

\section{REgIONAL CONSIDERATIONS}

Arguments for beneficence, non-maleficence, autonomy

Regions have been differentially affected by the COVID-19 pandemic. While highly populated cities with mass transit and dense urban areas have been devastated, the more rural, sparsely populated areas have seen a smaller "peak" in incidence. As with influenza-like illnesses and prior influenza pandemics, there are regional and geographic considerations that should drive the local decisions. ${ }^{[16]}$

Lessons learned from this pandemic regarding staffing, supply chains, and PPE support an alternate approach for our healthcare systems in the future. For regions outside of the pandemic, consideration of continuing surgical cases at a lower than pre-pandemic rate may be feasible, with appropriate precautions until there is evidence of increased regional infection prevalence. Individual surgical centers may be designated as "disease free" via a thorough screening processes for incoming patients, families, and employees. With screening and appropriate PPE for the employees, this designation may be reliably maintained. Also, by continuing to provide surgical services outside of the hospital, the community is served in the safest way possible.

Beneficence is maintained by attempts to protect healthier patients undergoing surgery from the patients under investigation (PUI) in the hospital. The patient's autonomy is preserved in that they may decide whether to proceed with their procedure. The patient is uniquely positioned to balance the risk to their health from either action (having surgery) or inaction (avoiding the potential community exposure). However, when the disease prevalence in the region increases, we return to primum non nocere: we cannot bring patients, or healthcare workers deliberately into harm's way to proceed with elective procedures.

Regions will also differ in their approach to recovery from a pandemic. Institutions will resume surgical care at variable rates. For smaller cities and rural areas, services may be permitted once appropriate screening measures are in place. Those most dramatically impacted, larger, urban areas, will likely be the last to reopen to routine surgical care. For the remainder of the country and areas with lower prevalence, an argument could be made for a rapid escalation of services for the overall health and well-being of our patients, our institutions, and our communities. With continuing respect for patient autonomy, the option for when and where to have surgery remains with the patient.

\section{ETHICAL ROLE OF INSURERS DURING A PANDEMIC}

As hospitals have been systematically emptied in preparation for a COVID-19 surge, insurance companies have not made their usual compensatory payouts. Insurance companies profit from the collection of premiums without distribution of payments to hospitals and surgeons. A significant decrease in the number of elective surgeries has drained hospitals of their primary revenue source to generate a positive margin. While institutions have been scavenging for now high cost protective gear and ventilation equipment, they must also absorb the costs associated with converting current facilities into acute care units during the pandemic. Ultimately, the healthcare institutions and the health insurance industry are functionally interdependent - healthcare institutions care for the industry's customers, and as such, the insurance industry is in part responsible for the financial well-being of the institution. The untapped resource of the collected, but undistributed, premiums and interest would require a partnership between healthcare institutions and the health insurance industry. A portion of the undistributed premiums and interest could be used to offset the unexpected increased operating costs associated with caring for those affected during this pandemic, compounded by lost surgical revenue. Both insurers and healthcare systems benefit from a healthy population receiving timely medical care.

\section{Conclusions}

COVID-19 represents the pandemic of our lifetime, and hospitals across our country and the world are impacted differently through a variety of factors. States and countries have instituted significant physical distancing and work re- 
strictions on their population, and medical societies have strongly suggested that hospitals stop elective surgical procedures. All this has resulted in substantial economic stress. Now that areas are approaching a plateau of the infectious burden to the community, mechanisms to support the financial sustainability of our hospitals and health systems are essential to continue to provide care to all. Multiple ethical principles should be utilized to guide our healthcare stakeholders incrementally towards returning elective cases to our operating rooms. By working towards efficiency, hospitals are better suited to support the community it serves. As surgeons, we must continue to operate on the basis beneficence, non-maleficence, and maintaining a healthy respect for our patient's autonomy. In times of strain, we must continue to offer and recommend the gold-standard of medical care and management but also understand the financial strain and limitation that may prohibit our patients from pursuing these options. While we have all been impacted by the changes and restrictions of this pandemic, surgical reintegration provides an opportunity to optimize surgical care during times of health and in future times of pandemic or natural disaster.

\section{CONFLicts OF INTEREST Disclosure}

The authors declare they have no conflicts of interest.

\section{REFERENCES}

[1] McKay B, Calfas J, Ansari T. Coronavirus declared pandemic by World Health Organization. Wall Street Journal. Published 2020 Updated March 11, 2020 [Accessed on April 10, 2020]. Available from: https://www.wsj.com/articles/u-s-coronavir us-cases-top-1-000-11583917794

[2] Luthi S. Surgeon General advises hospitals to cancel elec tive surgeries. Politico. Published 2020. Updated March 13, 2020 [Accessed on April 10, 2020]. Available from: https://www.politico.com/news/2020/03/14/surgeon-g eneral-elective-surgeries-coronavirus-129405

[3] COVID-19: Recommendations for Management of Elective Surgical Procedures. American College of Surgeons. Published 2020. Updated March 13, 2020 [Accessed on April 10, 2020]. Available from: https://www.facs.org/-/media/files/covid19/re commendations_for_management_of_elective_surgical_ procedures.ashx

[4] Beasley D. U.S. hospitals, patients cancel elective surgery as coronavirus spreads. Reuters. Published 2020. Updated March 16, 2020 [Accessed on April 10, 2020]. Available from: https://www.reuters.com/article/us-health-coronav irus-usa-surgery/u-s-hospitals-patients-cancel-ele ctive-surgery-as-coronavirus-spreads-idUSKBN2133SK

[5] Zhang S. What it really means to cancel elective surgeries: to make room for coronavirus patients, hospitals are delaying procedures that would make major differences in people's lives. The Atlantic. Accessed on April 7, 2020. Available from: https://www. theatl antic.com/science/archive/2020/03/patients-whose-s urgeries-are-canceled-because-coronavirus/608176/

[6] Lopes LKA, Hamel L, Brodie M. Data Note: Public Worries About And Experience With Surprise Medical Bills. KFF. Published 2020 Updated February, 28, 2020 [Accessed on April 6, 2020]. Available from: https://www.kff.org/health-costs/poll-finding /data-note-public-worries-about-and-experience-wit h-surprise-medical-bills/

[7] Gooch K. 300 safety-net hospitals call on Congress for financial relief amid coronavirus. Becker's Hospital Review. Published 2020. Updated March 18, 2020 [Accessed on April 6, 2020]. Available from: https://www.beckershospitalreview.com/finance/ 300-safety-net-hospitals-call-on-congress-for-fin ancial-relief-amid-coronavirus.html
[8] Weber L. Coronavirus Threatens The Lives Of Rural Hospitals Already Stretched To Breaking Point. Kaiser Health News. Published 2020. Updated March 21, 2020 [Accessed on April 6, 2020]. Available from: https://khn.org/news/coronavirus-threa tens-the-lives-of-rural-hospitals-already-stretch ed-to-breaking-point/

[9] 172 Rural Hospital Closures: January 2005 - Present (130 since 2010). UNC Sheps Center for Health Services Research. Updated 2020 [Accessed on April 6, 2020]. Available from: https://www. shepscenter.unc.edu/programs-proje cts/rural-health/rural-hospital-closures/

[10] Levine WC, Dunn PF. Optimizing Operating Room Scheduling. Anesthesiol Clin. 2015; 33(4): 697-711. PMid: 26610624. https : //doi.org/10.1016/j.anclin.2015.07.006

[11] Sokal SM, Craft DL, Chang Y, et al. Maximizing operating room and recovery room capacity in an era of constrained resources. Arch Surg. 2006; 141(4): 389-393; discussion 393-385. 12. PMid: 16618898. https://doi.org/10.1001/archsurg.141.4.389

[12] Xu R, Carty MJ, Orgill DP, et al. The teaming curve: a longitudinal study of the influence of surgical team familiarity on operative time. Ann Surg. 2013; 258(6): 953-957. PMid: 23407297. https://doi.org/10.1097/SLA.0b013e3182864ffe

[13] Stepaniak PS, Heij C, Buise MP, et al. Bariatric surgery with operating room teams that stayed fixed during the day: a multicenter study analyzing the effects on patient outcomes, teamwork and safety climate, and procedure duration. Anesth Analg. 2012; 115(6): 13841392. PMid: 23144431. https://doi.org/10.1213/ANE.0b01 3e31826c7fa6

[14] Stepaniak PS, Vrijland WW, de Quelerij M, et al. Working with a fixed operating room team on consecutive similar cases and the effect on case duration and turnover time. Arch Surg. 2010; 145(12): 1165-1170. PMid: 21173290. https://doi.org/10.1001/arch $\operatorname{surg} .2010 .255$

[15] Moawad NS, Santamaria E, Johnson M, et al. Cost-effectiveness of office hysteroscopy for abnormal uterine bleeding. JSLS: Journal of the Society of Laparoendoscopic Surgeons. 2014 Jul; 18(3). PMid: 25392645. https://doi.org/10.4293/JSLS. 2014.00393

[16] Qualls N, Levitt A, Kanade N, et al. Community Mitigation Guidelines to Prevent Pandemic Influenza - United States, 2017. MMWR Recomm Rep. 2017; 66(1): 1-34. PMid: 28426646. https://doi. org/10.15585/mmwr.rr6601a1 